\title{
MEETINGS OF COMMISSIONS
}

\section{COMMISSION 3. (NOTATIONS.)}

\author{
President: Prof. E. Strömgren. \\ SECRETARY: Mr Felix De Roy.
}

The President submitted to the Meeting, with some diffidence, the preliminary set of notations covering the whole field of astronomy, which he had prepared, and which had been printed in the Draft Report. It was, he said, a compromise between different systems of notations. He pointed to some misprints in the Draft Report and invited discussion.

Prof. Stroobant expressed his pleasure that the President had retained a number of the notations which he had presented at the Rome Meeting. While rendering homage to the completeness of the new scheme, he said that it had been submitted at too short a notice to allow a thorough discussion. He therefore proposed, at all events, to postpone a final decision.

Prof. Eddington and Prof. Russell agreed to this view, but emphasized the necessity of the new scheme being printed. They suggested some slight changes in a few of the proposed notations.

After some further discussion, the Commission adopted the following resolution, moved by Prof. Russell and seconded by Prof. Eddington:

I. That the preliminary list of notations prepared by the President of the Commission should be printed, with some alterations, in the Transactions of the Union, as a list provisionally recommended, and that all astronomers interested in the matter should be invited to suggest any changes thereto, by correspondence with the President of the Commission.

The meeting then took up resolution $(c)$ submitted to the Union by the National Committee of Belgium, which had been referred to them by the General Assembly.

Prof. Stroobant pointed to the great usefulness of the proposed supplement, which the Uccle Observatory is ready to prepare.

After some discussion, the following resolutions were carried:

2. That this Commission gives its sympathetic approval to the publication of a supplement, containing modifications and additions to the List of Observatories and Astronomers, published in I93I by the Royal Observatory, Uccle, under the auspices of the Union.

3. That the Union should, if practicable, devote a sum not exceeding Five Hundred Gold-Francs to assist in the publication of this supplement.

For a report of the joint meeting with Commission 4 see p. 286.

\section{COMMISSION 4. (EPHEMERIDES.)}

President: Dr L. J. Comrie.

SeCretary: Prof. A. KopfF.

A meeting with Commission 8 (Dr Jackson in the chair) was held to discuss two questions:

(a) Which stars are to be used in future as fundamental stars?

(b) What positions are to be used for these stars? 
The two systems available are the General Catalogue of Boss, with about 32,000 stars, and the $\mathrm{FK}_{3}$ of the Astronomisches Rechen-Institut, containing, with a supplement to be completed, I535 stars.

Prof. Boss remarked that the adoption of a single system by all the almanacs was highly desirable. The two systems were undertaken with different views; the $\mathrm{FK}_{3}$ was primarily designed to furnish fundamental positions of stars, whereas the General Catalogue had a considerably wider scope-to determine a better system of stars, and at the same time to furnish positions of as many stars as possible, and their proper motions, on one fundamental system. At the meeting in r932 the use of the General Catalogue as the system upon which photographic work should be based was recommended. He recommended the adoption of the $\mathrm{FK}_{3}$ for use in ephemerides.

Prof. Kopff said that the $\mathrm{FK}_{3}$ is a revision of the old catalogue of Auwers, and has about 900 stars. In the Berliner Jahrbuch for 1936 a list of about 600 additional stars is given, because the Auwers stars are too few in number and their distribution not sufficiently regular. Stars that cannot be observed with the meridian circle (especially double stars with distances between $0^{\prime \prime} \cdot 5$ and $5^{\prime \prime}$ ) are omitted. Bright stars, which are required for small instruments and for daylight observations, have been retained.

Prof. Schlesinger, speaking on behalf of photographic observers, said that there must be a fundamental system for photographic observations. One of the principal points to be considered in publishing photographic catalogues is to make quite sure that there is a strong tie between the positions as published and some well-known system. It was not for them to say what system is to be adopted, but they would like to call attention to the point that, if the stars in the system are bright, they are lost for measuring purposes. In a letter to Dr Comrie he had asked for the resumption of the Backlund-Hough list. This cannot be used at present, as the proper motions are not sufficiently well known; otherwise it would serve the purpose very well. The distribution is perfect; there are no very bright stars, the brightest being about 5.5. For use in ephemerides a different selection would perhaps be more acceptable. In reply to questions by $\mathrm{Dr}$ Jackson he admitted that they were not sufficiently numerous, and said he wished to have as many fundamental stars as possible. Dr Jackson remarked that the FK3 system is now the fundamental system of the photographic repetition of the northern sky by the Astronomische Gesellschaft.

Prof. Schlesinger moved and Dr Robertson seconded that "It is recommended that the $\mathrm{FK}_{3}$ be the fundamental catalogue to be used for the apparent places of stars in all astronomical ephemerides." This was carried unanimously.

At a meeting with Commissions 8 and 20 (Prof. Leuschner in the chair) the published plans of Dr Brouwer and Prof. Noumerov for the use of selected minor planets as a means of determining systematic corrections to star places were discussed. Prof. Leuschner said that, after discussing these plans very fully with Prof. Schlesinger, he had come to the conclusion that they must be regarded as being still in the experimental stage, but worthy of encouragement. He suggested the following resolution, which was offered by Prof. Schlesinger, seconded by Prof. Boss, and carried unanimously. "Commissions 4, 8 and 20 recommend that the programme of $M$. Noumerov for the determination of systematic corrections to star positions from observations of minor planets and the similar programme advanced by Dr Brouwer be encouraged as being of great importance, but that the formation of a sub-committee of one of the existing commissions or of an independent commission for the co-ordination of the two programmes and the promotion of 
international co-operation of observatories and planet institutes or almanac offices be deferred pending the outcome of the experimental stages of the two programmes."

At a meeting with Commission 20 (Prof. Leuschner in the chair) the equinox to be used in minor planet and cometary work was discussed. Prof. Leuschner summarised the replies to a questionnaire in which he had canvassed the views of observers and computers. There was a general demand for the continuation of facilities for referring first orbits to the equinox of the beginning of the year, together with a desire for the use of the equinox of $1950^{\circ} 0$ (and, in some cases, I900.0) in work of permanent value, namely definitive orbits and perturbations. The Nautical Almanac has published in a separate volume tables facilitating computations for the equinox of $195^{\circ} \circ$, and there was no suggestion that this equinox should be abandoned; on the contrary it was urged that publication of data for I950.0 should be continued. He considered it inadvisable to pass the resolution printed in the reports of Commissions 4 and 20 without the reservation that it should not apply to observations in the first apparition or opposition or to preliminary orbits. He reported that Commission 6 had already resolved to continue the equinox of the beginning of the year for telegraphic positions, although provision was made in the code for positions for other equinoxes, such as $1900^{\circ} 0$ or I950*0. Prof. Brown moved the adoption of the resolution amended in accordance with the reservations proposed by Prof. Leuschner.

Prof. Leuschner suggested that, for the present, some of the almanacs should continue publication of the solar co-ordinates and other data for the equinox of the beginning of the year. Dr Robertson and Prof. Kopff said that the American Ephemeris and the Berliner Jahrbuch would continue to give data for the equinox of the beginning of the year. Prof. Leuschner emphasised that the adoption of the proposed resolution would allow astronomers to retain much of their present freedom. It was perfectly natural that we should eventually drift to the equinox of $195^{\circ} \circ$, but it seemed too early to make the change. Dr Comrie said that, if the resolution was carried, it would appear that the Nautical Almanac had been premature in dropping the solar co-ordinates for the equinox of the beginning of the year; they would, therefore, be restored. The following two resolutions were then carried unanimously.

"The equinox used for observations of comets and minor planets in the first apparition or opposition, and for preliminary orbits, shall continue to be that of the beginning of the year, but from r938 January $I$ the equinox used for elements and ephemerides (with the above exceptions) shall be that of $195^{\circ} \circ$. Further, as from the same date, the equinox used in giving observed positions (with the above exceptions) of comets and minor planets shall be that of $1950^{\circ} \mathrm{O}$, unless the observer, for good reasons, uses some other equinox, and expressly draws attention to the equinox used."

"It is desirable that, for the present, some of the almanacs should continue publication of the data necessary for computing preliminary orbits and ephemerides referred to the equinox of the beginning of the year."

Prof. Leuschner, as a further result of the replies to his questionnaire, proposed that "It seems desirable to continue publication of the rectangular co-ordinates of the Sun to seven decimals, as this accuracy is essential when computing orbits of objects that come close to the Earth."

Prof. Kopff remarked that the Berliner Jahrbuch did not give so many decimals, and did not wish to give more, on the grounds that they are not necessary for preliminary work. Prof. Leuschner pointed out that the material in question was 
used also in the comparison of observations with theory. Dr Robertson said that the American Ephemeris would continue to give seven decimals. The resolution was then carried.

Prof. Leuschner then presented a recommendation emanating mainly from Russia, Poland and America, as follows: "It is recommended, on behalf of Commission 20 , that Commission 4 give early consideration to a formulated plan for the correction of the elements of the major planets, particularly of the Earth." He also intimated that, in the meantime, publication in the almanacs of the correction to be applied to the observed time before interpolating the solar co-ordinates, in order to counteract the error in longitude, would be helpful. Further, it would be a convenience to dynamical investigators if the elements of the major planets were published for some epoch of osculation.

Prof. Brown commented that it was scarcely feasible for a commission to undertake a piece of research like that of correcting the elements of a major planet; it had always been, and would continue to be, a matter for individual research. Secondly, we do not know that the deviations are due to inaccurate elements; they may be due to inequalities coming from insufficient calculation of the theory. The theory of Jupiter and Saturn may need slight corrections to the elements, and that would suffice, but it is fairly certain that Uranus and Neptune need a revision of the whole theory, and not merely correction of the elements. As for the four inner planets, an examination of Newcomb's work with reference to one or two points that are not quite clear would be sufficient, with perhaps an examination as to whether the elements need correction. All this should be pointed out to investigators rather than to Commission 4.

Dr Comrie pointed out that the Nautical Almanac for I936 gave, on page 78r, the time correction asked for by Prof. Leuschner. Prof. Leuschner remarked that he heartily endorsed Prof. Brown's views, as the original proposal was to be considered as applying not only to a revision of the elements but also to the theories. He expressed the hope that the proposed revisions would be the outcome of individual initiative. No formal action was taken.

Prof. Leuschner then opened a discussion on the proposal that accurate ephemerides of certain minor planets-particularly the first four-should be provided. Prof. Brown drew attention to the new theory of Vesta by Voronoff, which appeared, from the preliminary description already published, to have extremely high accuracy. It would be needed in the determination of the equinox, for which purpose accurate ephemerides must be provided. It is to be hoped that Voronoff's theory will be made available in the form of tables. An orbit of Juno is now being formed by Dr R. I. Wolff, a former pupil of his, but may not reach the stage of tables.

Dr Brouwer moved that "It is desirable that the calculation and publication of accurate ephemerides of the first four minor planets be undertaken and, if necessary, shared by various almanacs." In reply to a question by Prof. Leuschner as to whether the ephemerides should be based on general theories or on special perturbations, he emphasised that they should be of the highest possible quality, so that general theories were preferable.

Prof. Leuschner wished to utter a caution. When we speak of "accurate ephemerides" we often deceive ourselves as to their real accuracy. For instance Komendantoff has perfected the theory of Ceres and published in the Handbook of the British Astronomical Association ephemerides to $\mathrm{o}^{\text {s.OI }}$ and $\mathrm{o}^{\prime \prime} \cdot \mathrm{I}$, although these differ from observations by $3^{\text {s. }}$. The Handbook should have given some indication of the agreement to be expected; while the ephemeris was computed with precision 
by the extrapolation method, the basic heliocentric rectangular co-ordinates were derived from general tables that Komendantoff had not constructed with the high precision of his general theory, on which the tables are based. The results obtained from the tables of Villemarqué may be somewhat marred by the fact that accurate osculating elements had not always been used. He hoped that the almanacs, in publishing ephemerides, would also give full information regarding their probable accuracy. Prof. Kopff remarked that all such work must begin with accurate elements. He added that Dr Hans Osten is preparing a general theory of Pallas.

Dr Jones said that this matter is of very great importance to meridian observers, who would certainly welcome ephemerides of some of the brighter minor planets, provided that they are based on proper theories and accurate elements. They would be used for fixing the equinox and the equator point, which are now fixed by observations of the Sun and the major planets; these observations are necessarily made in the daytime, and are subject to systematic errors of various kinds. Following the suggestion of Dyson at Leiden in I928, observations of Vesta have been made at Greenwich, Washington and the Cape since that date, but it has not been possible to make use of them because of the absence of a satisfactory ephemeris. If the present proposal could be carried out, it would be of very great assistance indeed to meridian observers.

In reply to a question by Prof. Kepinski, Prof. Brown said that he considered it advisable, before beginning a general theory, to get a fairly good set of elements by special perturbations; such elements can be corrected in the process of forming the general theory, unless the changes are great. Prof. Kopff said that at the Astronomisches Rechen-Institut only approximate special perturbations by Jupiter, and, if necessary, by Saturn also, are applied, so that it is impossible to judge how accurate the elements are. Prof. Leuschner's Research Surveys, giving the history of each minor planet, would be particularly valuable.

Prof. Brown recalled that, when working on the orbit of Achilles, he had derived much assistance from Miss Vinter Hansen's work on the perturbations of that planet, particularly because elements were given at several intervals during the period covered. This permitted tests of the work at various stages, and he would like to encourage the practice of giving not only final elements but also elements at various intervening dates. Prof. Leuschner remarked that 20,000 sets of elements not published in the Research Surveys on account of expense had been transcribed, and were available.

In reply to a question by Dr Comrie concerning the observations of Vesta that have been made since 1928 , Dr Jones said that, if Voronoff's theory is made available in the form of tables, meridian circle observers would be very glad to have accurate ephemerides retrospectively. Dr Brouwer's motion was then carried unanimously.*

Prof. Leuschner suggested that the directors of the national ephemerides, separately or jointly, should publish a history of the changes made from the first volume to the present time. Dynamical investigators now have to look through many volumes in order to trace the various systems used. Prof. Brown, in supporting the proposal, suggested that, if the almanacs could not prepare a complete history, they might cover the ground partially; for instance a history of the changes in the ephemerides of the Sun and Moon alone would be of great help. Dr Comrie remarked that it does not always follow that the man who prepares the almanac and predicts

\footnotetext{
* Since the meeting Prof. Kopff has announced that the Astronomisches Rechen-Institut is prepared to give the ephemerides desired.
} 
for the future is the most suitable person to deal with the history of the past. At a later meeting of Commission 4 it was decided that the proposal should be referred to Commission 5 .

A joint meeting with Commission 3 (Prof. Strömgren in the chair) was held to consider two resolutions submitted to the General Assembly by National Committees, and referred to Commissions 3 and 4 .

(I) That the General Assembly be asked to explore the possibility of reducing the number of symbols used for astronomical time. (Great Britain.)

(2) Que l'Union fasse une démarche auprès de la direction du Nautical Almanac pour en obtenir que la dénomination de Greenwich Mean Time (G.M.T.) conserve son sens traditionnel, le Nautical Almanac consentant à remplacer ce terme par un terme nouveau s'il ne désire pas adopter l'expression Greenwich Civil Time (G.C.T.). (Belgium.)

Prof. Brown moved that "Commissions 3 and 4 recommend for international use Universal Time (U.T.), Temps Universel (T.U.) or Weltzeit for Greenwich Mean Time (G.M.T.) reckoned from midnight." He added that the British Nautical Almanac is obliged-for the present at any rate-to use G.M.T. Hence G.M.T. would be used in British official publications, and U.T. or T.U. elsewhere. G.C.T. would not be used anywhere. It has a doubtful meaning in England; in summer it would properly mean Summer Time, so that official English publications would naturally not use it.

Prof. Kopff said that Weltzeit is used throughout the Berliner Jahrbuch, and Prof. Strömgren said that U.T. is used exclusively in the Bureau for Astronomical Telegrams.

Dr Jones remarked that the Union had not placed a permanent ban on the use of G.M.T. The resolution passed at Leiden was that astronomers were advised "not to use the letters G.M.T. in any sense for the present." He agreed with Prof. Brown that it is not possible to use G.C.T. in Great Britain. The British National Committee is anxious to reduce the number of terms in use, and is prepared to accept as a compromise the term U.T.

Dr Comrie remarked that, as the use of G.M.T. in official British publications was compulsory, he hoped the recommendation would not preclude the use of G.M.T. in unofficial British publications. Prof. Brown, in reply, said that his resolution was a recommendation only, so that freedom to use G.M.T. in Great Britain still remained. The resolution was carried unanimously.

Dr Jones proposed further, in order to reduce the number of terms used, that "Commissions 3 and 4 recommend that in future Greenwich Civil Time (G.C.T.) should not be used." This was carried unanimously.

At the meeting of Commission 4 (Dr Comrie in the chair) the work done with other commissions was first summarised. Dr Comrie then reported, on behalf of the directors of the national ephemerides, on three proposals that were referred at the I932 meeting. (See Report, p. 29.) Prof. Kopff had consented, on behalf of the Berliner Jahrbuch, to alter the sign of the equation of time from I938 onwards. All ephemerides would then use the sign that enables the tabulated equation of time to be added algebraically to the known time to obtain the unknown time. In other words, if the argument is mean time, the equation of time is apparent time mimus mean time, and vice versa. In some ephemerides a time of transit is given, thus avoiding any question of sign. This report was adopted.

A uniform system for star positions, namely the $\mathrm{FK}_{3}$ and its supplement, was adopted at a joint meeting with Commission 8 . 
The third proposal was reported (Transactions I.A.U., 4, 222, 282) as follows: "It was moved and carried that the question of duplicate printing be referred to the directors of the principal almanacs, and that they be requested to report at the next meeting of the Union." That question was raised with special reference to apparent places of stars. The directors propose that each ephemeris should retain the apparent places of not more than 200 stars, the list being the same for all almanacs, and that the apparent places of the remaining stars should appear in a single volume, with an explanation in English, French and German. In dividing the work between different countries, it is evident that one country must do the entire printing. As no apparent places are at present computed by Great Britain, it is suggested that publication should be undertaken by that country, subject to the consent of the British Admiralty. The logical time to put this proposal into effect seems to be when the $\mathrm{FK}_{3}$ is used universally for the first time-perhaps in I940.

Prof. Kopff said that it is not yet certain that this volume can first appear in I940, as the appendix to the $\mathrm{FK}_{3}$ of 600 supplementary stars will not be finished for about three years.

Prof. Fayet asked whether, as the publication is necessarily of an international character, the title will describe it as being published under the auspices of the International Astronomical Union. Dr Robertson added that the volume should not appear as a purely British publication. Dr Comrie replied that, unless there were any objection on the part of the British Admiralty, it would certainly be regarded as being under the auspices of the Union.

Dr Robertson said that the volume should contain also the 200 bright stars. Prof. da Costa Lobo said that it should not be obligatory for any national almanac to print the 200 stars; if desired, none need be printed. In reply to a question by Mr Sadler, Dr Comrie said that the original report suggested the exclusion from the separate volume of the 200 stars. Profs. Fayet and Kopff and Drs Robertson and Miller urged that the volume should contain all the $\mathrm{FK}_{3}$ stars. In reply to Prof. Michkovitch, who asked if any almanac could publish more than 200 stars, Prof. Fayet said that the resolution would not preclude the publication of a greater number, the important thing being that the apparent places of all the ${ }_{535}$ stars should be in one volume.

Prof. Fayet moved, and it was carried unanimously, that "It is recommended that, as from the date of the adoption of the star places of the $\mathrm{FK}_{3}$, the apparent places of the $\mathrm{I}_{535}$ stars in the $\mathrm{FK}_{3}$ and its supplement be published in a single volume under the auspices of the International Astronomical Union, with all necessary explanations in English, French and German. It is recommended that the national ephemerides publish the apparent positions of not more than 200 stars, and that these stars be selected from the $\mathrm{FK}_{3}$. It is further recommended that the printing be undertaken by Great Britain, and the calculations shared by France, Germany, Spain and the United States."

Prof. Michkovitch described the difficulties that had prevented the appearance of the Belgrade Annuaire for 1935 (see Report, p. 29). He would be very grateful if a grant could be made for one year only, as this would show that the work was of international interest. Dr Comrie, remarking that presidents of commissions had been asked to be very careful about putting forward any applications for grants, asked if a resolution from the Union would be helpful. Prof. Brown said that the Union would not look with favour on any proposal for funds that should be disbursed by Governments. Prof. Brown then moved that "It is recommended that 
the Union urges the continued publication of the Belgrade Annuaire, which contains the apparent places of 240 stars not appearing in any other ephemeris, until such time as the apparent places of all fundamental stars are published in a single volume." This was carried unanimously.

Dr Comrie, referring to the 7 - and 8-figure tables prepared by Prof. Peters and himself, said that it was difficult to obtain the $£ 5000$ necessary for their printing, or even a smaller sum for subsidised publication. In reply to a question by Prof. Banachiewicz as to why six functions were not proposed, he said that each volume of four functions would run to more than 900 pages, and that a larger volume would be unwieldy. Dr Robertson moved, and it was carried unanimously, that the General Assembly be asked to adopt the following resolution: "That this Union considers early publication of the 7-and 8-figure tables of the four principal trigonometrical functions for every second of arc prepared by Prof. Peters and Dr Comrie to be highly desirable in the interests of science generally."

A proposal from Dr Smiley that the Commission should fix the value of the Gaussian constant $k$ was discussed. No ambiguity exists if not more than eight or nine significant figures are required, but conflict arises between the various natural and logarithmic values if ten or more significant figures are required. On the motion of Prof. Brown the President was asked to consult people known to be interested, and to report at the next meeting of the Union.

\title{
COMMISSION 5. (BIBLIOGRAPHY.)
}

\author{
President: M. P. Stroobant \\ SECRETARY: M. P. BoURgeoIS \\ Edition d'anciennes observations et de traductions de classiques \\ astronomiques (Almageste, Kopernikus, etc....)
}

M. Stroobant estime que les questions soulevées à ce sujet par MM. Dittrich, Brasch et Pogo sont du ressort de la Commission 2; cette Commission devant les difficultés matérielles que présentait pareille entreprise sous les auspices de I'U.A.I. a cessé son activité au Congrès de Rome (Ig22).

M. Lundmark estime que la question est importante, qu'il convient que l'U.A.I. s'y intéresse et que la Commission s'en occupe.

M. Collinder considère, d'expérience personnelle, que parfois, tout au moins en ce qui concerne certains ouvrages anciens importants au point de vue historique, une publication partielle serait suffisante.

La Commission décide de charger une sous-commission formée de MM. Stroobant, Brasch, Dittrich et Pogo de l'étude de la chose et particulièrement de la question des voies et moyens.

\section{Bibliographies}

A l'unanimité la Commission adopte la motion d'approbation proposée par M. Grouiller concernant la Bibliographie Mensuelle de l'Astronomie et figurant dans le rapport. Elle décide de soumettre à l'Assemblée Générale la résolution suivante: "Etant donné l'intérêt que présente la publication rapide de renseignements d'ordre bibliographique la Commission 5 demande à l'unanimité qu'une subvention de $£$ IOo soit attribuée à la Bibliographie Mensuelle de l'Astronomie." 